Purdue University

Purdue e-Pubs

$5-2010$

\title{
A Comprehensive Flow Regime Map for Microchannel Flow Boiling with Quantitative Transition Criteria
}

Tannaz Harirchian

Purdue University - Main Campus

S V. Garimella

Purdue University, sureshg@purdue.edu

Follow this and additional works at: http://docs.lib.purdue.edu/coolingpubs

Harirchian, Tannaz and Garimella, S V., "A Comprehensive Flow Regime Map for Microchannel Flow Boiling with Quantitative Transition Criteria" (2010). CTRC Research Publications. Paper 131.

http://dx.doi.org/10.1016/j.ijheatmasstransfer.2010.02.039

This document has been made available through Purdue e-Pubs, a service of the Purdue University Libraries. Please contact epubs@purdue.edu for additional information. 


\title{
A Comprehensive Flow Regime Map for Microchannel Flow Boiling with Quantitative Transition Criteria ${ }^{1}$
}

\author{
Tannaz Harirchian and Suresh V. Garimella ${ }^{2}$ \\ School of Mechanical Engineering and Birck Nanotechnology Center \\ 585 Purdue Mall, Purdue University \\ West Lafayette, IN 47907-2088 USA
}

\begin{abstract}
Due to the critical role of vapor confinement in establishing distinct flow and heat transfer characteristics in microchannels (as distinct from those in larger channels), the conditions under which such confinement occurs in microchannels are of great interest. It is shown in the present work that channel dimensions and flow properties alone, as proposed in past studies, are insufficient for determining confinement effects in microchannel boiling. Hence, a new criterion for physical confinement in microchannel flow boiling, termed the convective confinement number, that incorporates the effects of mass flux, as well as channel cross-sectional area and fluid properties, is proposed. This criterion helps determine the conditions under which a channel qualifies as a microchannel for two-phase flow, needing special treatment, and when a macroscale treatment is adequate. In addition, based on previous work by the authors, a new comprehensive flow regime map is developed for a wide range of experimental parameters and channel dimensions, along with quantitative transition criteria based on nondimensional boiling parameters.
\end{abstract}

\footnotetext{
${ }^{1}$ Submitted for possible publication in International Journal of Heat and Mass Transfer, August 2009

${ }^{2}$ Author to whom correspondence should be addressed: (765) 494-5621, sureshg@purdue.edu
} 


\section{NOMENCLATURE}

\begin{tabular}{|c|c|c|c|}
\hline$A_{c s}$ & cross-sectional area of a microchannel, $\mathrm{mm}^{2}$ & $q_{w}^{\prime \prime}$ & wall heat flux, $\mathrm{W} \mathrm{m}^{-2}$ \\
\hline$A_{f}$ & wetted area of a fin, $\mathrm{m}^{2}$ & $R e$ & Reynolds number $(\operatorname{Re}=G D / \mu)$ \\
\hline \multirow[t]{2}{*}{$A_{t}$} & total heated/wetted area of all microchannels & $T$ & temperature, ${ }^{\circ} \mathrm{C}$ \\
\hline & in a heat sink, $\mathrm{m}^{2}$ & $T_{r e f}$ & reference temperature: $T_{f}$ in single-phase \\
\hline$B l$ & boiling number ( $\left.B l=q_{w}^{\prime \prime} / G h_{f g}\right)$ & & region and $T_{s a t}$ in two-phase region, ${ }^{\circ} \mathrm{C}$ \\
\hline Bo & bond number $\left(B o=g\left(\rho_{f}-\rho_{g}\right) D^{2} / \sigma\right)$ & $w$ & microchannel width, $\mathrm{m}$ \\
\hline \multirow[t]{2}{*}{$d$} & microchannel depth, m & $w_{f}$ & microchannel fin width, $\mathrm{m}$ \\
\hline & & \multicolumn{2}{|c|}{ Greek symbols } \\
\hline$D$ & length scale $\left(\sqrt{A_{c s}}\right), \mathrm{m}$ & $\rho$ & density, $\mathrm{kg} \mathrm{m}^{-3}$ \\
\hline$D_{h}$ & hydraulic diameter, $\mu \mathrm{m}$ & $\mu$ & dynamic viscosity, $\mathrm{kg} \mathrm{m}^{-1} \mathrm{~s}^{-1}$ \\
\hline$g$ & gravitational acceleration & $\sigma$ & surface tension, $\mathrm{N} \mathrm{m}^{-1}$ \\
\hline$G$ & mass flux, $\mathrm{kg} \mathrm{m}^{-2} \mathrm{~s}^{-1}$ & $\eta_{f}$ & efficiency of a fin in the microchannel heat \\
\hline$h$ & heat transfer coefficient, $\mathrm{W} \mathrm{m}{ }^{-2} \mathrm{~K}^{-1}$ & & sink \\
\hline$h_{f g}$ & latent heat of vaporization for $\mathrm{FC}-77, \mathrm{~J} \mathrm{~kg}^{-1}$ & $\eta_{o}$ & overall surface efficiency of the \\
\hline$k_{s i}$ & thermal conductivity of silicon $\mathrm{W} \mathrm{m} \mathrm{m}^{-1} \mathrm{~K}^{-1}$ & & microchannel heat sink \\
\hline$L$ & microchannel length, m & Subs & pts \\
\hline \multirow[t]{2}{*}{$m$} & used in fin efficiency calculation & $f$ & liquid \\
\hline & $\left(m=\sqrt{2 h / k_{s i} w_{f}}\right), \mathrm{m}^{-1}$ & $g$ & vapor \\
\hline MAPE & mean absolute percentage error & sat & saturated liquid \\
\hline$N$ & number of microchannels in a test piece & $w$ & microchannel wall \\
\hline$\dot{q}_{n e}$ & heat dissipated to the fluid, W & & \\
\hline
\end{tabular}

Keywords: Microchannel flow boiling, confinement effects, cross-sectional area, microchannel size, flow regime map, transition criteria

\section{INTRODUCTION}

In flow boiling through channels, as the channel size decreases to approach the bubble diameter, physical confinement begins to modify the influence of the different governing forces, resulting in different behavior of boiling in microchannels compared to that in conventional-sized channels. 
Kandlikar [1] classified channels with hydraulic diameters between 10 to $200 \mu \mathrm{m}$ as microchannels for flow boiling, based merely on dimensions and not on physical behavior. Kew and Cornwell [2] proposed a criterion for a threshold hydraulic diameter below which microchannel two-phase flow is characterized by confined single bubbles; the available models for macroscale boiling were found to be unsuitable for the prediction of heat transfer and pressure drop at these small channel sizes. Serizawa et al. [3] recommended a confinement criterion similar to that of Kew and Cornwell representing the ratio of surface tension and gravity forces for the channel size below which the influence of surface tension becomes important. These confinement criteria [2,3] include channel hydraulic diameter and fluid properties; however, it will be shown from the results obtained from the current study that mass flux also governs bubble confinement. A new criterion for the occurrence of vapor confinement in flow boiling in microchannels is proposed that incorporates mass flux as well as channel cross-sectional area and fluid properties based on these results.

Flow regime maps are commonly used to determine the flow patterns that exist under different operating conditions, as well as the conditions for flow pattern transitions. Such maps are essential to the development of flow regime-based models for the prediction of the heat transfer rate and pressure drop in flow boiling. The coordinates used to plot these flow regime maps can be superficial phase velocities or derived parameters containing these velocities; however, the effects of important parameters such as channel size are not represented in a number of these maps. Baker [4], Hewitt and Roberts [5], and Taitel and Dukler [6] developed early flow regime maps for horizontal and vertical two-phase flow in channels with diameters of a few centimeters. In recent years, a few studies [7-11] have developed flow regime maps for boiling in microchannels using similar axes as conventional maps with flow regime definitions pertinent to microscale boiling, and have shown that flow regime maps developed for larger tubes are inapplicable for predicting flow regime transitions in microchannels. Flow regime maps for adiabatic two-phase flow in microchannels have also been proposed through high-speed visualizations [12-14]; however, it has been shown [9] that adiabatic flow regime maps are not suitable for the prediction of microscale boiling. Despite the inability of macroscale boiling maps or adiabatic two-phase flow regime maps to predict the boiling flow patterns in microchannels, a review of the literature shows a dearth of 
investigations into flow regime maps specifically targeted at microchannels undergoing flow boiling that are applicable to a wide range of microchannel dimensions and experimental conditions.

In recent work by the authors [15-17], the effects of microchannel dimensions and mass flux on flow boiling regimes and heat transfer rates were investigated. Experiments were conducted with the perfluorinated dielectric fluid, Fluorinert FC-77, over a wide range of channel dimensions and mass fluxes. The microchannel width, aspect ratio, and hydraulic diameter in these experiments ranged from $100 \mu \mathrm{m}$ to $5850 \mu \mathrm{m}, 0.27$ to 15.55 , and $96 \mu \mathrm{m}$ to $707 \mu \mathrm{m}$, respectively, and the mass flux ranged from 225 to $1420 \mathrm{~kg} / \mathrm{m}^{2} \mathrm{~s}$. The dependence of the boiling heat transfer coefficient on vapor quality was also investigated in detail for a number of refrigerants [18]. In [16], two types of flow regime maps were developed, one on mass flux-vapor quality coordinates and the other on vapor-liquid superficial velocity coordinates. However, the flow regime maps represented in these coordinate systems depend on channel dimensions, and therefore, individual maps were developed for each channel size.

This review of the literature shows that existing flow regime maps for boiling in microchannels are limited to narrow ranges of channel sizes and have been developed for water and refrigerants. In the present work, a new type of comprehensive flow regime map for microchannel flow boiling is developed for a wide range of experimental parameters and channel dimensions for FC-77; quantitative transition criteria based on nondimensional parameters are also proposed. Also, a new criterion for the definition of a microchannel based on the presence or absence of confinement effects in flow boiling is proposed.

\section{EXPERIMENTAL SETUP AND TEST PROCEDURES}

In this section, key details of the experiments on which the present comprehensive flow regime map and vapor confinement transition criterion are based are explained. More details of the test section assembly, flow loop, and calibration procedures are available in Harirchian and Garimella [15].

The test loop consists of a magnetically coupled gear pump, a preheater installed upstream of the test section to heat the coolant to the desired subcooling temperature, and a water-to-air heat exchanger located downstream of the test section to cool the fluid before it enters a reservoir (Figure 1). The liquid is fully degassed before initiating each test using two degassing ports and the expandable reservoir. 
Details of the expandable reservoir design and the degassing procedure are available in Chen and Garimella [19]. A flow meter with a measurement range of 20-200 $\mathrm{ml} / \mathrm{min}$ monitors the flow rate through the loop and five T-type thermocouples are utilized to measure the fluid temperature at different locations in the loop. The pressure in the outlet manifold of the test section is maintained at 1 atmosphere. The pressure in the inlet manifold and the pressure drop across the microchannel array are measured using a pressure transducer (Gems Sensors, 2200 series) and a differential pressure transducer (Omega, PX2300 series), respectively.

The microchannel test piece shown in Figure 2(a) consists of a $12.7 \mathrm{~mm} \times 12.7 \mathrm{~mm}$ silicon substrate mounted on a printed circuit board (PCB). Parallel microchannels of rectangular cross-section are cut into the top surface of the silicon chip using a dicing saw. A polycarbonate top cover positioned above the test piece and sealed with an O-ring provides enclosed passages for the liquid through the microchannels (Figure 2(b)).

Twelve test pieces, with microchannel widths ranging from $100 \mu \mathrm{m}$ to $5850 \mu \mathrm{m}$ and depths ranging from $100 \mu \mathrm{m}$ to $400 \mu \mathrm{m}$, all having a channel length of $12.7 \mathrm{~mm}$, are included in the experimental investigation. The aspect ratio and hydraulic diameter of the microchannels in the different test pieces take values from 0.27 to 15.55 and $96 \mu \mathrm{m}$ to $707 \mu \mathrm{m}$, respectively. The width (w), depth (d), and number $(\mathrm{N})$, along with the hydraulic diameter $\left(\mathrm{D}_{\mathrm{h}}\right)$, aspect ratio $(\mathrm{w} / \mathrm{d})$, and single channel cross-sectional area $\left(A_{c s}\right)$ of the microchannels in each test piece are summarized in Table 1. The average roughness of the bottom wall of the microchannels ranges from 0.8 to $1.4 \mu \mathrm{m}$ for the different test pieces as measured by an optical profilometer; the bottom wall of the $100 \mu \mathrm{m}$-wide microchannels has a lower average roughness of $0.1 \mu \mathrm{m}$ since a single dicing cut was used in their fabrication.

A $5 \times 5$ array of individually addressable resistance heat sources is fabricated on the underside of the silicon chip. In the present work, a uniform heat flux is provided to the base of the microchannels. Since the resistances of all 25 heat sources are measured to be almost identical, they are connected in parallel and are supplied with a single DC voltage in order to provide a uniform heat flux. Also, a like array of temperature-sensing diodes facilitates local measurements of the base temperature. For a given current passing through a diode temperature sensor, the voltage drop across the diode determines the wall 
temperature. Details of the integrated resistance heaters and diode temperature sensors, as well as the procedures used to calibrate the heaters and sensors, are provided in [15].

Experiments are conducted with 12 test pieces to study the effects of microchannel dimensions on the boiling heat transfer and flow patterns for four mass fluxes ranging from 225 to $1420 \mathrm{~kg} / \mathrm{m}^{2} \mathrm{~s}$. Before initiating each test, the liquid in the test loop is fully degassed. It is then driven into the loop at a constant flow rate and preheated to approximately $92^{\circ} \mathrm{C}$, providing $5^{\circ} \mathrm{C}$ of subcooling at the inlet of the channels. For each test, the flow rate and the inlet fluid temperature are kept constant throughout the test and the uniform heat flux provided to the chip is incremented from zero to the point at which the maximum wall temperature reaches $150^{\circ} \mathrm{C}$, which is the upper limit for the safe operation of the test chips. Heat flux values approaching critical heat flux are not used in the experiments since the corresponding temperatures could cause the solder bumps in the test chip to fail.

Fully degassing the liquid in the test loop before initiating each test helps to minimize flow instabilities. Also, a valve positioned upstream of the test section serves to suppress instabilities in the microchannel heat sink. Mild flow reversals were still observed at the inlet of the microchannels at the highest heat fluxes studied, for microchannels of cross-sectional area $0.144 \mathrm{~mm}^{2}$ and smaller; however, these instabilities did not affect the inlet fluid temperature, which is held constant throughout each test.

At each heat flux and after the system reaches a steady state, high-speed visualizations are performed simultaneously with the heat transfer and pressure drop measurements. Movies of the flow patterns are captured at various frame rates ranging from 2,000 frames per second (fps) to 24,000 fps, with the higher frame rates used for the smaller microchannels at the larger heat and mass fluxes. The images obtained from the camera are then post-processed using a MATLAB [20] code developed in-house to enhance the quality of the images, especially for those captured at higher frame rates.

\subsection{Data reduction}

The local heat transfer coefficient is calculated from

$$
h=\frac{q_{w}^{\prime \prime}}{\eta_{o}\left(T_{w}-T_{r e f}\right)}
$$


where $T_{\text {ref }}$ is the local mean fluid temperature in the single-phase region and the liquid saturation temperature in the two-phase region. $\eta_{o}$ is the overall surface efficiency of the microchannels defined as $\eta_{o}=1-\frac{N A_{f}}{A_{t}}\left(1-\eta_{f}\right)$, where $A_{f}=2 L d$ is the wetted area of a fin and $\eta_{f}=\frac{\tanh m d}{m d}$ is the efficiency of a fin with an adiabatic tip. The heat flux used in Eq. (1) is the wall heat flux and is defined as

$$
q_{w}^{\prime \prime}=\dot{q}_{n e t} /\left(A_{t} / 25\right)
$$

where $A_{t}$ is the total heated area of the microchannels

$$
A_{t}=N(w+2 d) L
$$

The net heat transfer rate to the fluid, $\dot{q}_{n e t}$, is obtained from the energy balance for each heating element:

$$
\dot{q}_{\text {net }}=\dot{q}-\dot{q}_{\text {loss }}
$$

in which $\dot{q}$ is the total heat dissipated from each heat source and $\dot{q}_{\text {loss }}$ is the heat loss which is experimentally determined before the test assembly is charged with coolant. Further details of the heat loss measurement procedure and data reduction can be found in Harirchian and Garimella [15]. The heat loss values range from $7 \%$ to $50 \%$ of the net heat transfer rate for different test pieces and different mass fluxes, and are larger for wider microchannels at lower mass fluxes.

The calculated local heat transfer coefficients presented in this paper are based on measurements from the temperature sensor located along the centerline of the test piece near the exit. In general, boiling starts at the downstream end of the microchannels and two-phase flow does not cover the whole length of the microchannels at low heat fluxes. In this study, the local values are reported for the location near the exit of the central microchannels.

Important nondimensional parameters often used in flow boiling include Reynolds number, $R e$, Bond number, $B o$, and Boiling number, $B l$. The Reynolds number is calculated using the liquid phase mass flux as:

$$
R e=\frac{G D}{\mu_{f}}
$$


The Bond number represents the ratio of buoyancy force to surface tension force and becomes important in microscale boiling:

$$
B o=\frac{g\left(\rho_{f}-\rho_{g}\right) D^{2}}{\sigma}
$$

As demonstrated in Harirchian and Garimella [17], the channel cross-sectional area plays a critical role in determining microchannel boiling mechanisms and heat transfer; therefore, the length scale used in equations (5) and (6) is the square root of the cross-sectional area of one channel rather than its hydraulic diameter. Boiling number is the nondimensional form of the heat flux and is calculated using the liquid mass flux and latent heat as follows:

$$
B l=\frac{q_{w}^{\prime \prime}}{G h_{f g}}
$$

The measurement uncertainties for the flow meter and the pressure transducers are $1 \%$ and $0.25 \%$ of full scale, respectively. The uncertainties in the measurement of the channel dimensions, the T-type thermocouples and the diode temperature sensors are $\pm 15 \mu \mathrm{m}, \pm 0.3^{\circ} \mathrm{C}$ and $\pm 0.3^{\circ} \mathrm{C}$, respectively. Following a standard uncertainty analysis [21], the uncertainties associated with the wall heat flux and the heat transfer coefficient are estimated to be 2.0 to $11.4 \%$ and 2.2 to $11.7 \%$, respectively, for the cases considered, with the larger uncertainties occurring for smaller microchannels at lower heat fluxes. These uncertainties are primarily governed by uncertainties in the measurement of the wetted surface area, since the uncertainties in the net heat transfer rate, wall temperature, and saturation temperature are relatively small.

\section{RESULTS AND DISCUSSION}

As mentioned in the introduction, a systematic investigation of boiling flow patterns and heat transfer with respect to microchannel dimensions and mass flux was recently performed by the authors $[16,17]$ and it was shown that confinement effects are present below a threshold value of channel cross-sectional area for a fixed mass flux [17]. In the present work, a criterion is developed for the existence of physical confinement in microchannel boiling based on channel dimensions, mass flux and fluid properties. The effects of vapor confinement on the boiling heat transfer coefficient are then discussed. Finally, a 
comprehensive flow regime map is developed based on approximately 390 experimental data points [16, 17].

\subsection{Microscale phenomena}

There has been a good deal of discussion in the literature regarding the appropriate definition of a microchannel; however, a clear, physics-based distinction of microchannels from conventional-sized channels has not emerged. In general, a microchannel refers to a channel for which the heat transfer coefficient and pressure drop deviate from the predictions from widely accepted models for conventionalsized channels. For single-phase flow, Liu and Garimella [22] and Lee et al. [23] showed that channels with hydraulic diameters as small as $244 \mu \mathrm{m}$ (the minimum considered in the studies) still exhibit heat transfer and pressure drop behavior that is well-predicted by conventional models. With boiling present in the channels, however, the flow phenomena differ from those in macroscale channels as the channel approaches the bubble diameter in size. In these small channels, correlations and models developed for larger channels no longer apply [24]. In this section, a new criterion is developed for delineating microchannels from macroscale channels based on the presence of vapor confinement.

In Harirchian and Garimella [16], flow visualizations were performed with simultaneous heat transfer measurements during flow boiling in microchannels of different sizes for different flow rates. Five flow regimes - bubbly, slug, churn, wispy-annular, and annular flow - were identified in these microchannels and reference may be made to that paper for photographs, schematic diagrams and detailed descriptions of the regimes. The changes in flow regimes with microchannel size and mass flux were discussed in detail. Figure 3 shows a summary of the existing flow regimes at different microchannel sizes and different mass fluxes. It is seen that in the smaller microchannels and at low mass fluxes, bubbly flow is not established; instead, slug flow is observed for low heat fluxes. In slug flow, elongated vapor bubbles are confined within the channel cross-section and are separated from the walls by a thin liquid layer. As the heat flux is increased, an alternating churn and confined annular flow appears in these microchannels. In the confined annular flow, the vapor core occupies the whole cross-section of the microchannels and is separated from the walls by a thin liquid film. 
As the channel cross-sectional area or the mass flux increases, bubbly flow is observed at low heat fluxes. In the bubbly flow regime, bubbles are smaller relative to the cross section of the channels and multiple bubbles may occupy the channel; confinement is not observed. At higher heat fluxes, alternating churn and wispy-annular or annular flow occurs. In the wispy-annular or annular flow, the vapor core does not necessarily occupy the entire cross-section and can instead exist on only one side of the channel; in other words, the flow is not confined by the channel walls. For example, the annular flow and churn flow patterns are distributed side by side across the width of the channel for channels with a large aspect ratio, as explained in [16].

The experimental flow visualizations reveal that the flow confinement depends not only on the channel size, but also on the mass flux since the bubble diameter varies with flow rate. The different experimental cases listed in Table 1 for various channel sizes and mass fluxes are categorized into two groups of confined and unconfined flow regardless of the heat input, and are represented in Figure 4 on Reynolds number and Bond number coordinates. This plot shows that for channels of small crosssectional area and at low mass fluxes, vapor confinement is observed, while for larger microchannels and at high mass fluxes, the flow is not confined. The solid line on this plot shows the transition between confined and unconfined flow and is a curve fit to the transition points, represented by

$$
B o^{0.5} \times R e=\frac{1}{\mu_{f}}\left(\frac{g\left(\rho_{f}-\rho_{g}\right)}{\sigma}\right)^{0.5} G D^{2}=160
$$

$B o^{0.5} \times R e$, a parameter named the convective confinement number here, is proportional to the mass flux, $G$, and the cross-sectional area, $D^{2}$, and is inversely proportional to the fluid surface tension. This new flow boiling transition criterion recommends that for $B o^{0.5} \times R e<160$, vapor bubbles are confined and the channel should be considered as a microchannel. For larger convective confinement numbers, the flow does not experience physical confinement by the channel walls and the channel can be considered as a conventional (macroscale) channel. It is important to note that this transition criterion is independent of the heat flux and is very useful in determining whether a channel behaves as a microchannel or a conventional, macroscale channel, regardless of the heat input, for practical applications. 
comprehensive flow regime map accounting for the heat input which determines the specific flow patterns is presented in section 3.3.

The proposed criterion for transition between confined and unconfined flow is compared in Figure 5 with available experimental observations from other studies in the literature for water $[1,3,7,25-31]$, dielectric liquids [32-35], and refrigerants [36]. Details of the fluid, geometry, mass flux, and heat flux of the data points used in this comparison are listed in Table 2. Figure 5 shows that the proposed criterion is successful in predicting the confined or unconfined nature of the flow from a variety of studies in the literature.

The effects of the physical confinement by the channel walls on the heat transfer coefficient are discussed next.

\subsection{Effect of vapor confinement on the heat transfer coefficient}

The experimentally determined heat transfer coefficients for various microchannel sizes and four mass fluxes in the range of 225 to $1420 \mathrm{~kg} / \mathrm{m}^{2} \mathrm{~s}$ are plotted in Figure 6. At the mass flux of $225 \mathrm{~kg} / \mathrm{m}^{2} \mathrm{~s}$, vapor confinement is visually observed in microchannels with cross-sectional area of $0.258 \mathrm{~mm}^{2}$ (corresponding to the $700 \mu \mathrm{m} \times 400 \mu \mathrm{m}$ microchannels) and smaller. Figure 6(a) shows that the heat transfer coefficients for the microchannels with such flow confinement are larger in the low heat flux region. As explained in Harirchian and Garimella [17], for the confined flow (i.e., slug flow at low heat fluxes), evaporation of the thin liquid film at the walls contributes to the heat transfer, and nucleate boiling is not the only boiling mechanism. This leads to higher heat transfer coefficient values. At higher heat fluxes, where annular flow exists in all channel sizes, heat transfer coefficients in small microchannels approach those of larger channels in value.

For the mass flux of $630 \mathrm{~kg} / \mathrm{m}^{2} \mathrm{~s}$, flow visualizations reveal confinement in microchannels smaller than $250 \mu \mathrm{m} \times 400 \mu \mathrm{m}$ [17]. Correspondingly, Figure 6(b) shows that the heat transfer coefficients in these microchannels depend on the channel dimensions, and also take values that are higher relative to those in larger microchannels, increasing with decreasing channel cross-sectional area [17]. For microchannels with cross-sectional area of $0.089 \mathrm{~mm}^{2}$ and larger, in which confinement is not visually 
observed and nucleate boiling is dominant, the heat transfer coefficient is independent of channel dimensions.

At a higher mass flux of $1050 \mathrm{~kg} / \mathrm{m}^{2} \mathrm{~s}$, slug flow and vapor confinement are seen only in the $100 \mu \mathrm{m} \times$ $400 \mu \mathrm{m}$ microchannel, and all other microchannels exhibit similar values of heat transfer coefficient regardless of the channel size (Figure 6(c)). For the largest mass flux tested of $1420 \mathrm{~kg} / \mathrm{m}^{2} \mathrm{~s}$, vapor confinement is not observed for any of the microchannels considered, and Figure 6(d) shows an independence of the heat transfer coefficient on channel dimensions.

The plots in Figure 6 show that for the channels in which confinement is not present and nucleate boiling is dominant up to very high heat fluxes, and for which the convective confinement number $B o^{0.5} \times R e$ is larger than 160 , the heat transfer coefficient is independent of microchannel size and all the curves collapse on to a single curve. For microchannel dimensions and mass fluxes which result in $B o^{0.5} \times R e<160$, the heat transfer coefficients are larger due to the contribution of thin film evaporation to the heat transfer mechanisms.

In a previous work by the authors [15], the experimental results for the heat transfer coefficient were compared to predictions from a number of existing correlations in the literature developed for macrochannel flow boiling, microchannel flow boiling, and for pool boiling. It was shown that for most of the cases studied in that work (now determined to have $B o^{0.5} \times R e>160$ ), the nucleate pool boiling correlation of Cooper [37] predicted the experimental results very well, with a mean absolute percentage error of $7.2 \%$. For smaller microchannels at lower mass fluxes (which would exhibit vapor confinement according to the criterion proposed here), the error associated with the prediction of heat transfer coefficient using this correlation was larger at 15\%; however, this correlation still predicted the experimental results better than other empirical correlations developed specifically for microchannel flow boiling.

It can be concluded that for $B o^{0.5} \times R e>160$ where vapor confinement is not detected, the heat transfer is governed by bubble nucleation, and the nucleate pool boiling correlation of Cooper [37] is suitable for heat transfer predictions. For channel sizes and mass fluxes with smaller convective 
confinement numbers, vapor confinement and microscale effects become important, resulting in larger errors in the prediction of heat transfer coefficient using nucleate boiling correlations. Other existing empirical correlations do not seem to be suitable for prediction of heat transfer in these microchannels either, and flow regime-based models need to be developed to accurately account for the microscale effects and the differences in the heat transfer phenomena compared to macroscale boiling mechanisms $[24,38]$.

\subsection{Comprehensive flow regime map}

In recent work by the authors [16], two different types of flow regime maps for microchannel flow boiling of FC-77 were developed based on the experimentally visualized flow patterns. Twelve different flow regime maps were plotted for the six channel dimensions considered using coordinates of mass flux vapor quality and of liquid superficial velocity and vapor superficial velocity. Both types of flow regime maps depend on channel dimensions; hence, for each channel dimension, a separate flow regime map is required to capture the flow regime transitions accurately. The effects of channel width on the flow regime transition were discussed as well. The flow regime maps developed in [16] were also compared to flow transitions from other studies in the literature for adiabatic two-phase flow and for boiling in macroand micro-channels. It was concluded that only the flow regime maps developed for microscale flow boiling in comparable channel sizes could reasonably match the observed flow transitions. A review of the literature reveals that despite the inability of macroscale boiling maps and adiabatic two-phase flow maps to predict the flow patterns for boiling in microchannels, there is a lack of flow regime maps developed for microchannel flow boiling for a range of channel dimensions.

Due to dependence of flow regimes (and regime maps) on channel dimensions, it is important to include the effects of channel size in the flow regime maps. To address this need, a comprehensive flow regime map is developed here.

Figure 7 shows the comprehensive flow regime map developed based on the experimental results and flow visualizations performed with FC-77. The abscissa in this plot is the convective confinement number, $B o^{0.5} \times R e$, which is proportional to $G \times D^{2}$. The ordinate is a nondimensional form of the 
heat flux, $B l \times R e$, which is proportional to $q_{w}^{\prime \prime} \times D$. Plotting all the $\sim 390$ experimental data points obtained in [16] and [17] for 12 different microchannel test pieces, four mass fluxes, and heat fluxes in the range of 25 to $380 \mathrm{~kW} / \mathrm{m}^{2}$ on $B l \times R e$ versus $B o^{0.5} \times R e$ logarithmic axes leads to a comprehensive flow regime map with four distinct regions of confined slug flow, churn/confined annular flow, bubbly flow, and churn/annular/wispy-annular flow.

The vertical transition line is given by $B o^{0.5} \times R e=160$, which represents the transition to confined flow. The other transition line is a curve fit to the points of transition from bubbly or slug flow to alternating churn/annular or churn/wispy-annular flow, given by

$$
B l \times R e=0.017\left(B o^{0.5} \times R e\right)^{0.7}
$$

which can be rearranged to give

$$
B l=0.017\left(B o^{0.4} \times R e^{-0.3}\right)
$$

This flow regime map shows that for $B o^{0.5} \times R e<160$ vapor confinement is observed in both slug and churn/annular flow regimes while for $B o^{0.5} \times R e>160$, the flow is not confined. For low heat fluxes with $B l<0.017\left(B o^{0.4} \times R e^{-0.3}\right)$, flow patterns of slug (if $B o^{0.5} \times R e<160$ ) or bubbly (if $B o^{0.5} \times R e>160$ ) flow exist in the microchannels. At higher heat fluxes with $B l>0.017\left(B o^{0.4} \times R e^{-0.3}\right)$, vapor bubbles coalesce resulting in a continuous vapor core in the alternating churn/annular or churn/wispy annular flow regimes.

In Figure 8, experimental data from a range of other studies in the literature are plotted on this comprehensive flow regime map. The map developed here is clearly able to represent the flow regimes found in the literature for water and fluorocarbon liquids.

\section{CONCLUSIONS}

Based on the experimental results obtained in recent work by the authors, a new transition criterion is developed which predicts the conditions under which microscale confinement effects are exhibited in flow boiling. This criterion depends on the value of a parameter termed the convective confinement 
number in this study, $B o^{0.5} \times R e$, which depends not only on the channel dimensions and fluid properties, but also on the mass flux. It is shown that for flow boiling of FC-77, physical confinement in the microchannels exists for convective confinement numbers less than 160; under this condition, thin film evaporation contributes to heat transfer in addition to nucleate boiling, and results in larger values of heat transfer coefficient compared to those cases in which no confinement is observed and nucleate boiling is dominant.

A comprehensive flow regime map for flow boiling of FC-77 is developed with approximately 390 data points encompassing a wide range of microchannel dimensions with channel cross-sectional area in the range of $0.009-2.201 \mathrm{~mm}^{2}$, mass flux in the range of $225-1420 \mathrm{~kg} / \mathrm{m}^{2} \mathrm{~s}$, and heat flux in the range of $25-380 \mathrm{~kW} / \mathrm{m}^{2}$. The convective confinement number, $B o^{0.5} \times R e$, and a nondimensional form of heat flux, $B l \times R e$, are used as the abscissa and the ordinate of this map, respectively. Using these coordinates, the flow regime map reveals four distinct regions of confined slug, bubbly, churn/confined annular, and churn/annular/wispy-annular flow regimes with two transition lines. One transition line, $B o^{0.5} \times R e=160$, represents the transition to confined flow, while the other transition line, $B l=0.017\left(B o^{0.4} \times R e^{-0.3}\right)$, which includes the effects of heat flux, illustrates the transition from bubbly/confined slug flow to alternating churn/annular/wispy-annular flow.

For $B o^{0.5} \times R e>160$, where physical confinement does not occur in flow boiling, the heat transfer coefficient is independent of channel dimensions and can be accurately predicted by a nucleate pool boiling correlation; however, for convective confinement numbers below 160, modified empirical correlations or regime-based models are required to more precisely account for the microscale effects present.

The proposed confinement transition criterion and the comprehensive flow regime map developed are shown to capture trends observed in the experimental data from the literature as well, and show good agreement with results for water and fluorocarbon liquids. While the convective confinement number criterion and the flow regime map have been shown to be very promising tools for predicting the flow regimes and their transitions in microchannel boiling, only limited studies are available for comparison, as 
both visualized flow boiling patterns in microchannels as well as heat flux data are necessary for such comparisons. As more well-characterized data become available, it will be possible to further generalize this confinement criterion and to expand the applicability of the comprehensive flow regime map to other fluids.

\section{Acknowledgements}

Financial support from the State of Indiana $21^{\text {st }}$ Century Research and Technology Fund and from the Cooling Technologies Research Center, an NSF Industry/University Cooperative Research Center at Purdue University, is gratefully acknowledged. The authors thank Bruce Myers of Delphi Electronics and Safety, Kokomo, Indiana, for providing the silicon test pieces.

\section{REFERENCES}

[1] Kandlikar, S. G., 2002. Fundamental Issues Related to Flow Boiling in Minichannels and Microchannels. Experimental Thermal and Fluid Science 26, 389-407.

[2] Kew, P. A. and Cornwell, K., 1997. Correlations for the Prediction of Boiling Heat Transfer in SmallDiameter Channels. Applied Thermal Engineering 17, 705-715.

[3] Serizawa, A., Feng, Z., and Kawara, Z., 2002. Two-Phase Flow in Microchannels, Experimental Thermal and Fluid Science 26 (6-7), 703-714.

[4] Baker, O., 1954. Design of Pipe Lines for Simultaneous Flow of Oil and Gas. Oil and Gas Journal 26.

[5] Hewitt, G. F. and Robert, D. N., 1969. Studies of Two-Phase Flow Patterns by Simultaneous X-Ray and Flash Photography. AERE-M 2159, HMSO.

[6] Taitel, Y. and Dukler, A. E. 1976. A Model for Predicting Flow Regime Transitions in Horizontal and Near Horizontal Gas-liquid Flow. AIChE Journal 22, 47-55.

[7] Hetsroni, G., Mosyak, A., Segal, Z., and Pogrebnyak, E., 2003. Two-Phase Flow Patterns in Parallel Microchannels. International Journal of Multiphase Flow 29, 341-360.

[8] Huo, X., Chen, L., Tian, Y.S., and Karayiannis, T. G., 2004. Flow Boiling and Flow Regimes in Small Diameter Tubes. Applied Thermal Engineering 24, 1225-1239.

[9] Revellin, R., Dupont, V., Ursenbacher, T., Thome, J. R., and Zun, I., 2006. Characterization of Diabatic Two-Phase Flows in Microchannels: Flow Parameter Results for R-134a in a $0.5 \mathrm{~mm}$ Channel. International Journal of Multiphase Flow 32, 755-774. 
[10] Revellin, R. and Thome, J. R., 2007. A New Type of Diabatic Flow Pattern Map for Boiling Heat Transfer in Microchannels. Journal of Micromechanics and Microengineering 17, 788-796.

[11] Ong, C. L. and Thome, J. R., 2009. Flow Boiling Heat Transfer of R134a, R236fa and R245fa in a Horizontal 1.030 mm Circular Channel. Experimental Thermal and Fluid Science 33, 651-663.

[12] Chung, P. M.-Y. and Kawaji, M., 2004. The Effect of Channel Diameter on Adiabatic Two-Phase Flow Characteristics in Microchannels. International Journal of Multiphase Flow 30 (7-8), 735-761.

[13] Hassan, I., Vaillancourt, M., and Pehlivan, K., 2005. Two-Phase Flow Regime Transitions in Microchannels: a Comparative Experimental Study. Microscale Thermophysical Engineering 9, 165-182.

[14] Field, B. and Hrnjak, P., 2007. Visualization of Two-Phase Refrigerant and Refrigerant-Oil Flow in a Microchannel. ASME International Mechanical Engineering Congress and Exposition, IMECE200743471, Seattle, WA.

[15] Harirchian, T. and Garimella, S. V., 2008. Microchannel Size Effects on Local Flow Boiling Heat Transfer to a Dielectric Fluid. International Journal of Heat and Mass Transfer 51, 3724-3735.

[16] Harirchian, T. and Garimella, S. V., 2009. Effects of Channel Dimension, Heat Flux, and Mass Flux on Flow Boiling Regimes in Microchannels. International Journal of Multiphase Flow 35, 349-362.

[17] Harirchian, T. and Garimella, S. V., 2009. The Critical Role of Channel Cross-Sectional Area in Microchannel Flow Boiling Heat Transfer. International Journal of Multiphase Flow 35, 904-913.

[18] Bertsch, S. S., Groll, E. A., and Garimella, S. V., 2008. Refrigerant Flow Boiling Heat Transfer in Parallel Microchannels as a Function of Local Vapor Quality. International Journal of Heat and Mass Transfer 51, 4775-4787.

[19] Chen, T. and Garimella S. V., 2006. Effect of Dissolved Air on Subcooled Flow Boiling of a Dielectric Coolant in a Microchannel Heat Sink. Journal of Electronic Packaging 128 (4), 398-404.

[20] MATLAB software, www.mathworks.com

[21] Taylor, J. R., 1997. An Introduction to Error Analysis, $2^{\text {nd }}$ Edition. University Science Books.

[22] Liu, D. and Garimella, S. V., 2004. Investigation of Liquid Flow in Microchannels. Journal of Thermophysics and Heat Transfer 18 (1), 65-72.

[23] Lee, P. S., Garimella, S. V., and Liu, D., 2005. Investigation of Heat Transfer in Rectangular Microchannels. International Journal of Heat and Mass Transfer 48, 1688-1704.

[24] Bertsch, S. S., Groll, E. A., and Garimella, S. V., 2008. Review and Comparative Analysis of Studies on Saturated Flow Boiling in Small Channels. Nanoscale and Microscale Thermophysical Engineering $12,187-227$.

[25] Peles, Y. P., Yarin, L. P., and Hetsroni, G., 1999. Evaporating Two-Phase Flow Mechanism in Microchannels. Proceedings of SPIE 3680, 226-236.

[26] Jiang, L., Wong, M., and Zohar, Y., 2001. Forced Convection Boiling in a Microchannel Heat Sink. Journal of Microelectromechanical Systems 10, 80-87. 
[27] Lee, M., Wong, Y. Y., Wong, M., and Zohar, Y., 2003. Size and Shape Effects on Two-Phase Flow Patterns in Microchannel Forced Convection Boiling. Journal of Micromechanics and Microengineering $13,155-164$.

[28] Steinke, M. E. and Kandlikar S. G., 2003. Flow Boiling and Pressure Drop in Parallel Flow Microchannels. First International Conference on Microchannel and minichannels, Rochester, NY, ICMM2003-1070.

[29] Zhang, L., Wang, E. N., Goodson, K. E., and Kenny, T. W., 2005. Phase Change Phenomena in Silicon Microchannels. International Journal of Heat and Mass Transfer 48, 1572-1582.

[30] Garimella, S. V., Singhal, V., and Liu, D., 2006. On-Chip Thermal Management with Microchannel Heat Sinks and Integrated Micropumps. Proceedings of IEEE 94 (8), 1534-1548.

[31] Wang, G., Cheng, P., Bergles, A. E., 2008. Effects of Inlet/Outlet Configurations on Flow Boiling Instability in Parallel Microchannels. International Journal of Heat and Mass Transfer 51, 2267-2281.

[32] Hetsroni, G., Mosyak, A., Segal, Z., and Ziskind, G., 2002. A Uniform Temperature Heat Sink for Cooling of Electronic Devices. International Journal of Heat and Mass Transfer 45, 3275-3286.

[33] Mukherjee, S. and Mudawar I., 2003. Smart Pumpless Loop for Micro-Channel Electronic Cooling Using Flat and Enhanced Surfaces. IEEE Transactions on Components and Packaging Technologies 26 (1), 99-109.

[34] Zhang, H. Y., Pinjala, D., and Wong T. N., 2005. Experimental Characterization of Flow Boiling Heat Dissipation in a Microchannel Heat Sink with Different Orientations. Proceeding of $7^{\text {th }}$ Electronics Packaging Technology Conference, EPTC 2, 670-676.

[35] Chen, T. and Garimella, S. V., 2006. Measurements and High-Speed Visualization of Flow Boiling of a Dielectric Fluid in a Silicon Microchannel Heat Sink. International Journal of Multiphase Flow 32 (8), 957-971.

[36] Coleman, J. W. and Garimella S., 2003. Two-phase Flow Regimes in Round, Square and Rectangular Tubes during Condensation of Refrigerant R134a. International Journal of Refrigeration 26, 117-128.

[37] Cooper, M. G., 1984. Saturated Nucleate Pool Boiling - a Simple Correlation. $1^{\text {st }}$ UK National Heat Transfer Conference, IChemE Symposium Series 2 (86), 785-793.

[38] Garimella, S. V. and Sobhan, C. B., 2003. Transport in Microchannels - a Critical Review. Annual Review of Heat Transfer 13, 1-50. 


\section{LIST OF TABLES}

Table 1. Microchannel dimensions and mass fluxes (the microchannel widths and depths are referred to in the rest of the paper by the nominal values that are provided in the table; similarly, the four mass fluxes are referred to in the rest of the paper by the nominal values of $225,630,1050$, and $\left.1420 \mathrm{~kg} / \mathrm{m}^{2} \mathrm{~s}\right)$.

Table 2. Summary of the experimental data from the literature used in the comparisons of the confinement transition criterion and of the flow regime map.

\section{LIST OF FIGURES}

Figure 1. Photograph of the experimental facility.

Figure 2. (a) Microchannel test chip, and (b) test section assembly.

Figure 3. Summary of boiling flow patterns in the microchannel test pieces; the microchannel dimensions are presented as width $(\mu \mathrm{m}) \times$ depth $(\mu \mathrm{m})$ with a single-channel cross-sectional area $\left(\mathrm{mm}^{2}\right)$ in parentheses.

Figure 4. Transition from confined flow to unconfined flow.

Figure 5. Comparison of the confinement criterion with experimental data from a variety of sources in the literature.

Figure 6. Effects of physical confinement on heat transfer coefficients for four mass fluxes; the microchannel dimensions are presented as width $(\mu \mathrm{m}) \times$ depth $(\mu \mathrm{m})$.

Figure 7. Comprehensive flow regime map for FC-77.

Figure 8. Comparison of the comprehensive flow regime map with the experimental data from the literature. 
Table 1. Microchannel dimensions and mass fluxes (the microchannel widths and depths are referred to in the rest of the paper by the nominal values that are provided in the table; similarly, the four mass fluxes are referred to in the rest of the paper by the nominal values of $225,630,1050$, and $1420 \mathrm{~kg} / \mathrm{m}^{2} \mathrm{~s}$ ).

\begin{tabular}{ccccccc}
\hline $\begin{array}{c}\mathrm{w}(\mu \mathrm{m}) \\
(\text { actual values })\end{array}$ & $\begin{array}{c}\mathrm{d}(\mu \mathrm{m}) \\
(\text { actual values })\end{array}$ & $\mathrm{N}$ & $\begin{array}{c}\mathrm{D}_{\mathrm{h}} \\
(\mu \mathrm{m})\end{array}$ & $\mathrm{w} / \mathrm{d}$ & $\begin{array}{c}\mathrm{A}_{\mathrm{cs}} \\
\left(\mathrm{mm}^{2}\right)\end{array}$ & $\begin{array}{c}\mathrm{G} \\
\left(\mathrm{kg} / \mathrm{m}^{2} \mathrm{~s}\right)\end{array}$ \\
\hline $100(99)$ & $100(94)$ & 61 & 96 & 1.05 & 0.009 & 660 \\
$100(97)$ & $220(217)$ & 63 & 134 & 0.45 & 0.021 & 630 \\
$100(102)$ & $400(369)$ & 60 & 159 & 0.27 & 0.037 & $214,621,1017,1405$ \\
$250(240)$ & $400(371)$ & 35 & 291 & 0.64 & 0.089 & $226,611,1126,1415$ \\
$400(398)$ & $100(65)$ & 25 & 111 & 6.12 & 0.026 & 615 \\
$400(400)$ & $220(197)$ & 25 & 264 & 2.03 & 0.079 & 637 \\
$400(395)$ & $400(365)$ & 24 & 379 & 1.08 & 0.144 & $227,633,1031,1431$ \\
$700(686)$ & $400(376)$ & 14 & 486 & 1.83 & 0.258 & $225,641,1053,1461$ \\
$1000(1024)$ & $220(226)$ & 10 & 370 & 4.53 & 0.231 & 630 \\
$1000(978)$ & $400(374)$ & 10 & 541 & 2.62 & 0.366 & $224,627,1037,1440$ \\
$2200(2203)$ & $400(370)$ & 5 & 634 & 5.95 & 0.815 & $227,633,1034,1427$ \\
$5850(5851)$ & $400(376)$ & 2 & 707 & 15.55 & 2.201 & $229,632,1028,1289$ \\
\hline
\end{tabular}


Table 2. Summary of the experimental data from the literature used in the comparisons of the confinement transition criterion and of the flow regime map.

\begin{tabular}{|c|c|c|c|c|}
\hline Reference & Fluid & Geometry & $\underset{\left(\mathrm{kg} / \mathrm{m}^{2} \mathrm{~s}\right)}{\text { Mass flux }}$ & $\begin{array}{l}\text { Wall heat flux } \\
\left(\mathrm{kW} / \mathrm{m}^{2}\right)\end{array}$ \\
\hline $\begin{array}{c}\text { Peles et al. [25] } \\
1999\end{array}$ & Water & $\begin{array}{l}\text { Parallel microchannels } \\
\mathrm{Dh}=157,207 \mu \mathrm{m}\end{array}$ & $\begin{array}{l}3500 \\
6000\end{array}$ & - \\
\hline $\begin{array}{l}\text { Jiang et al. [26] } \\
2001\end{array}$ & DI Water & $\begin{array}{l}\text { Parallel grooves } \\
\qquad \mathrm{w}=50 \mu \mathrm{m}\end{array}$ & $110-365$ & - \\
\hline Kandlikar [1] 2002 & DI Water & $\begin{array}{l}\text { Parallel microchannels } \\
\mathrm{w}=1 \mathrm{~mm}, \mathrm{~d}=1 \mathrm{~mm}\end{array}$ & 40 & - \\
\hline $\begin{array}{l}\text { Serizawa et al. [3] } \\
2002\end{array}$ & DI Water & $\begin{array}{l}\text { Circular tube } \\
\mathrm{D}=50 \mu \mathrm{m}\end{array}$ & 24 & - \\
\hline Lee et al. [27] 2003 & DI Water & $\begin{array}{l}\text { Parallel microchannels } \\
\mathrm{w}=120 \mu \mathrm{m}, \mathrm{d}=14 \mu \mathrm{m}\end{array}$ & $30-60$ & - \\
\hline $\begin{array}{l}\text { Hetsroni et al. [7] } \\
2003\end{array}$ & Water & $\begin{array}{l}\text { Parallel triangular microchannels } \\
\qquad D_{\mathrm{h}}=103,129 \mu \mathrm{m}\end{array}$ & $87-108$ & $80-220$ \\
\hline $\begin{array}{l}\text { Steinke and } \\
\text { Kandlikar [28] } \\
\quad 2003\end{array}$ & DI Water & $\begin{array}{l}\text { Parallel microchannels } \\
\mathrm{w}=214 \mu \mathrm{m}, \mathrm{d}=200 \mu \mathrm{m}\end{array}$ & $115-467$ & $55-839$ \\
\hline $\begin{array}{l}\text { Zhang et al. [29] } \\
\qquad 2005\end{array}$ & DI Water & $\begin{array}{l}\text { Single microchannel } \\
\mathrm{w}=50 \mu \mathrm{m}, \mathrm{d}=40 \mu \mathrm{m}\end{array}$ & 160 & - \\
\hline $\begin{array}{l}\text { Garimella et al. } \\
\text { [30] } 2006\end{array}$ & DI Water & $\begin{array}{l}\text { Parallel microchannels } \\
\mathrm{w}=275 \mu \mathrm{m}, \mathrm{d}=636 \mu \mathrm{m}\end{array}$ & 651 & 160 \\
\hline $\begin{array}{l}\text { Wang et al. [31] } \\
\qquad 2008\end{array}$ & DI Water & $\begin{array}{l}\text { Parallel trapezoidal microchannels } \\
\mathrm{w}=208,427 \mu \mathrm{m}, \mathrm{d}=146 \mu \mathrm{m}\end{array}$ & $91-787$ & 365,486 \\
\hline $\begin{array}{l}\text { Hetsroni et al. [32] } \\
2002\end{array}$ & $\begin{array}{l}\text { Vertrel } \\
\text { XF }\end{array}$ & $\begin{array}{l}\text { Parallel triangular } \\
\text { microchannels } \\
\mathrm{Dh}=130 \mu \mathrm{m}\end{array}$ & 148 & 36 \\
\hline $\begin{array}{l}\text { Mukherjee and } \\
\text { Mudawar [33] } \\
\quad 2003\end{array}$ & FC-72 & $\begin{array}{l}\text { Parallel mini- and microchannels } \\
\text { in a gap, } \mathrm{w}=200 \mu \mathrm{m}, \mathrm{d}=660 \mu \mathrm{m} \\
\quad \mathrm{w}=1.57 \mathrm{~mm}, \mathrm{~d}=3.05 \mathrm{~mm}\end{array}$ & $500-1100$ & - \\
\hline $\begin{array}{l}\text { Zhang et al. [34] } \\
\qquad 2005\end{array}$ & FC-72 & $\begin{array}{l}\text { Parallel microchannels } \\
\mathrm{w}=200 \mu \mathrm{m}, \mathrm{d}=2000 \mu \mathrm{m}\end{array}$ & 120 & 42 \\
\hline $\begin{array}{l}\text { Chen and } \\
\text { Garimella [35] } \\
2006\end{array}$ & FC-77 & $\begin{array}{c}\text { Parallel microchannels } \\
\mathrm{w}=389 \mu \mathrm{m}, \mathrm{d}=389 \mu \mathrm{m}\end{array}$ & 345 & $9-56$ \\
\hline $\begin{array}{l}\text { Coleman and } \\
\text { Garimella [36] } \\
2003\end{array}$ & $\mathrm{R} 134 \mathrm{a}$ & $\begin{array}{c}\text { Glass tube } \\
\mathrm{w}=4.9 \mathrm{~mm}\end{array}$ & 150,750 & - \\
\hline
\end{tabular}




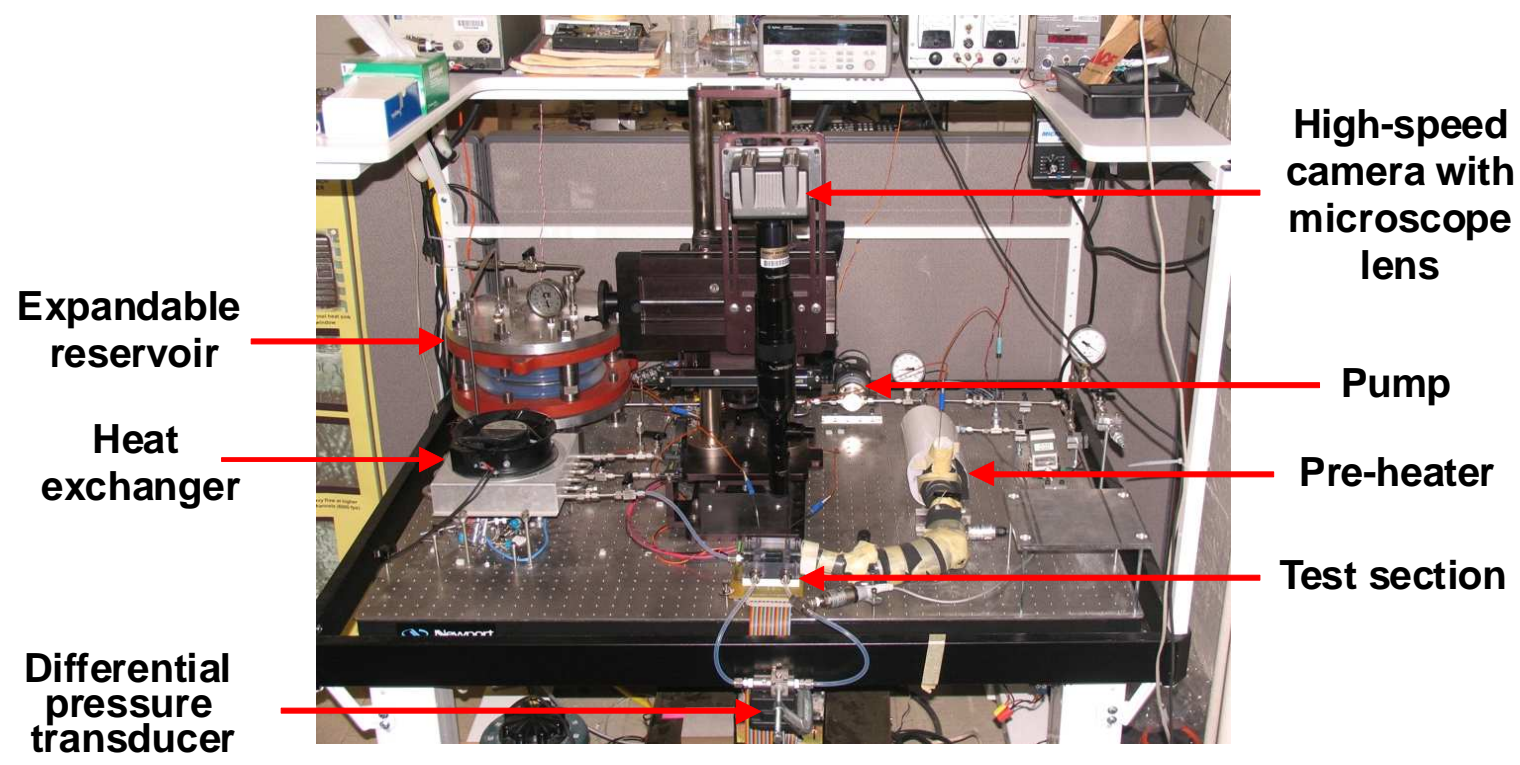

Figure 1. Photograph of the experimental facility. 


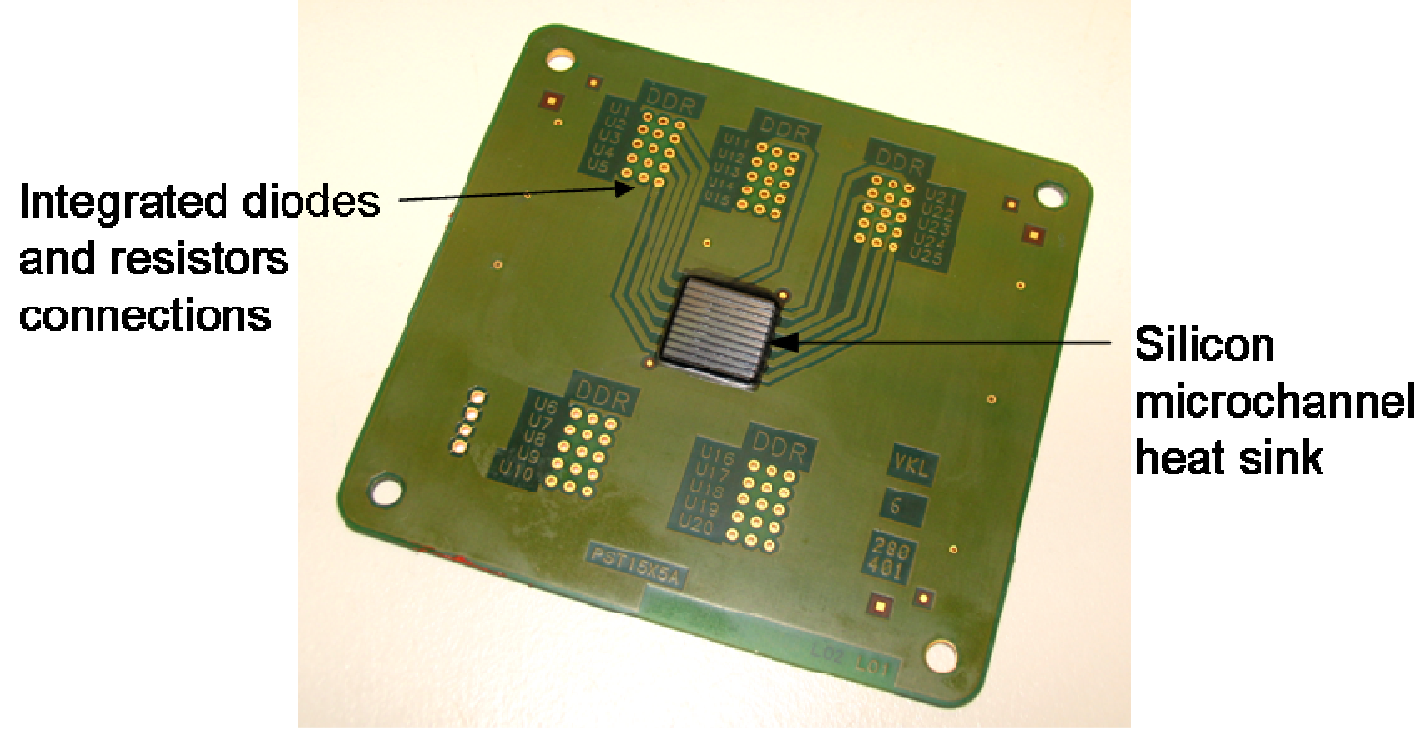

(a)

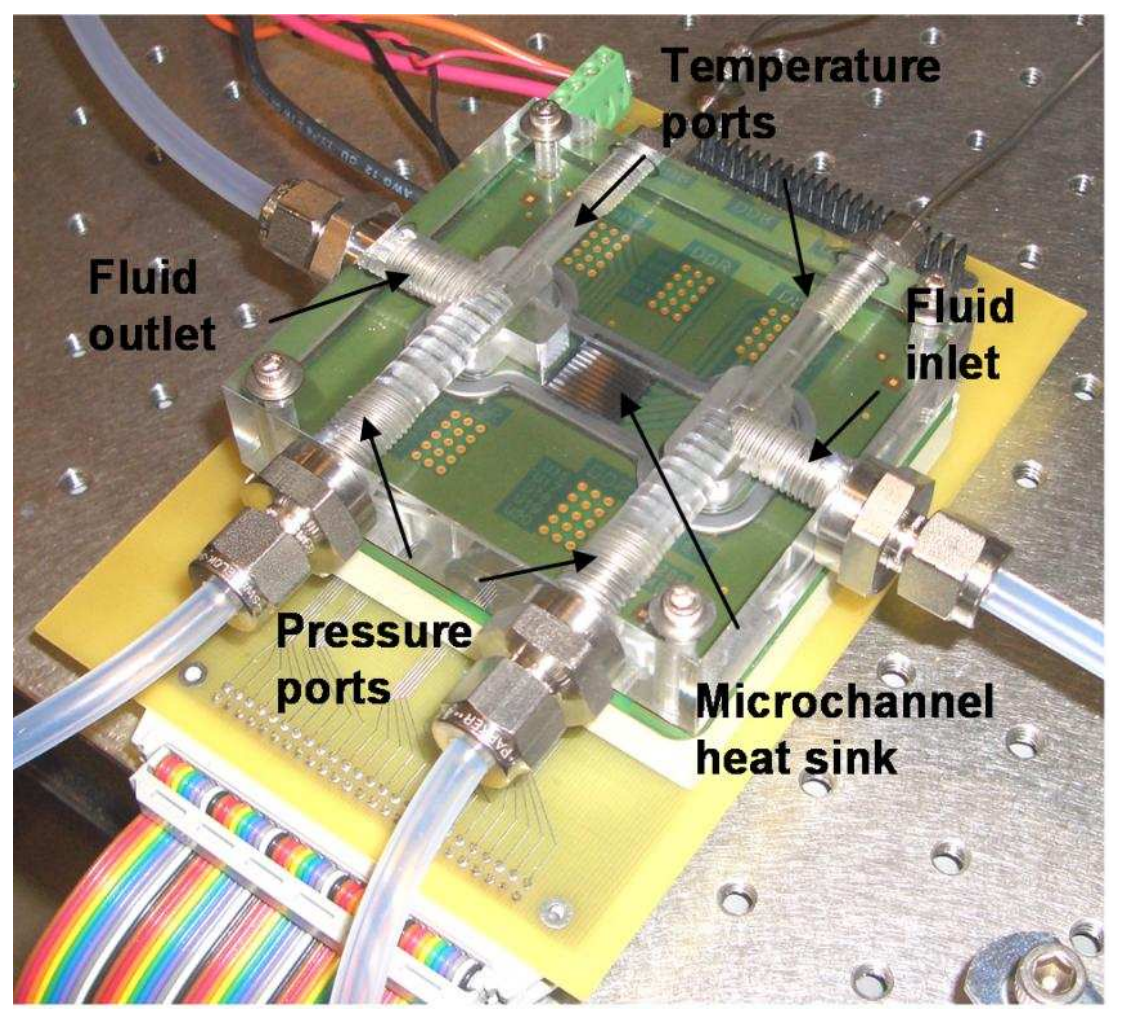

(b)

Figure 2. (a) Microchannel test chip, and (b) test section assembly. 


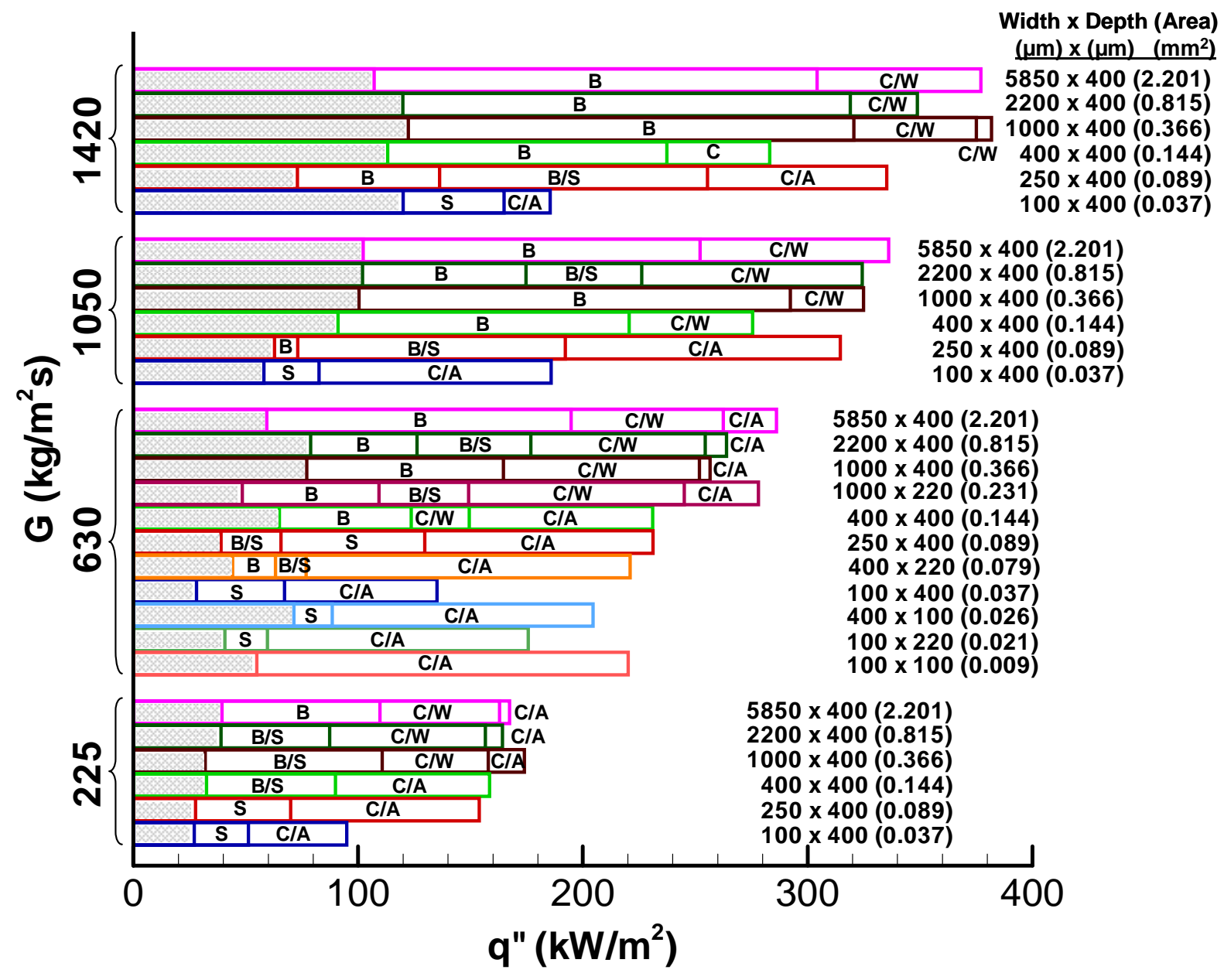

B: Bubbly S: Slug C: Churn W: Wispy-annular A: Annular
B/S: Alternating bubbly/slug flow
C/W: Alternating churn/wispy-annular flow
C/A: Alternating churn/annular flow
: Single-phase flow

Figure 3. Summary of boiling flow patterns in the microchannel test pieces; the microchannel dimensions are presented as width $(\mu \mathrm{m}) \times$ depth $(\mu \mathrm{m})$ with a single-channel cross-sectional area $\left(\mathbf{m m}^{2}\right)$ in parentheses. 


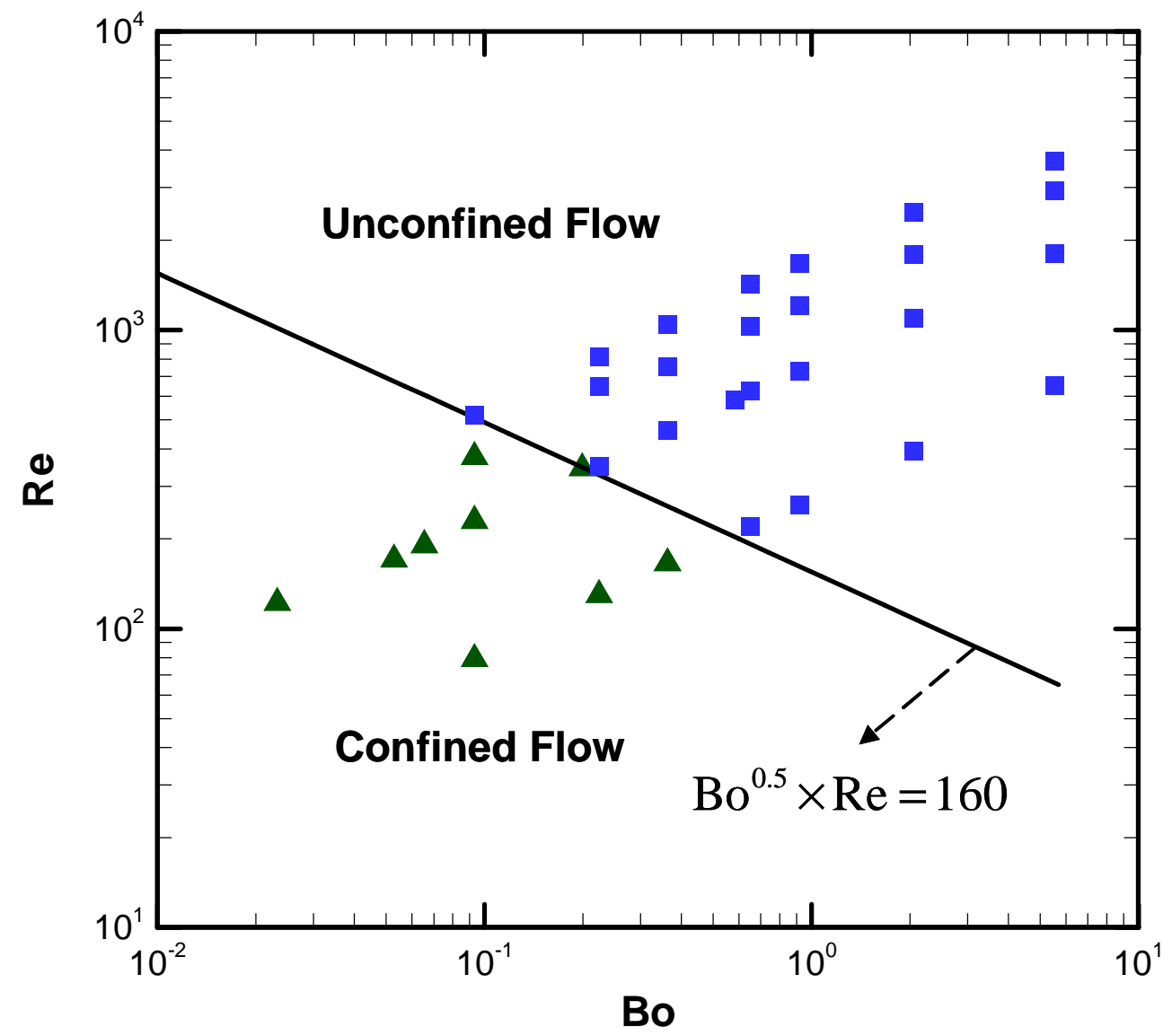

Figure 4. Transition from confined flow to unconfined flow. 


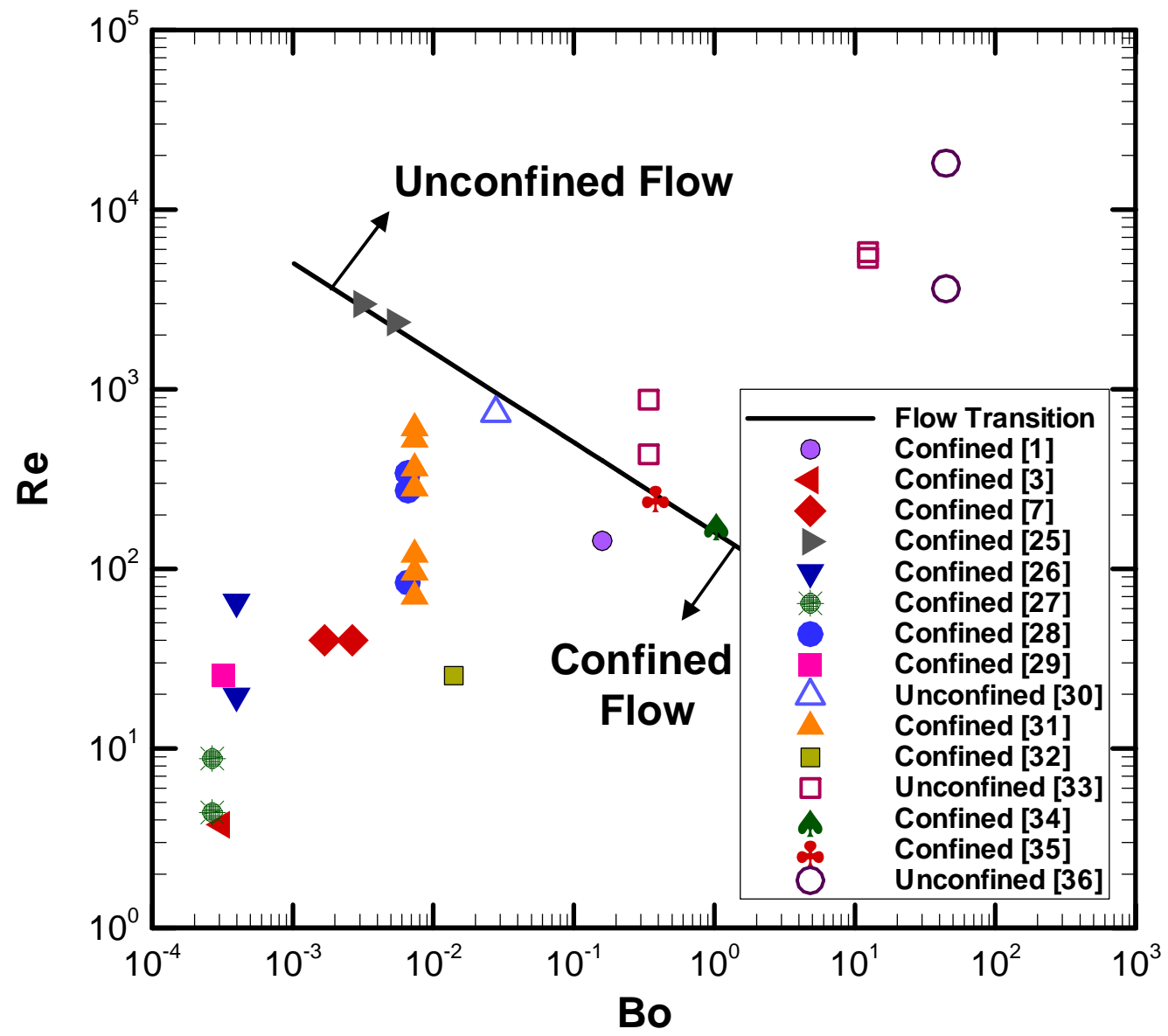

Figure 5. Comparison of the confinement criterion with experimental data from a variety of sources in the literature. 

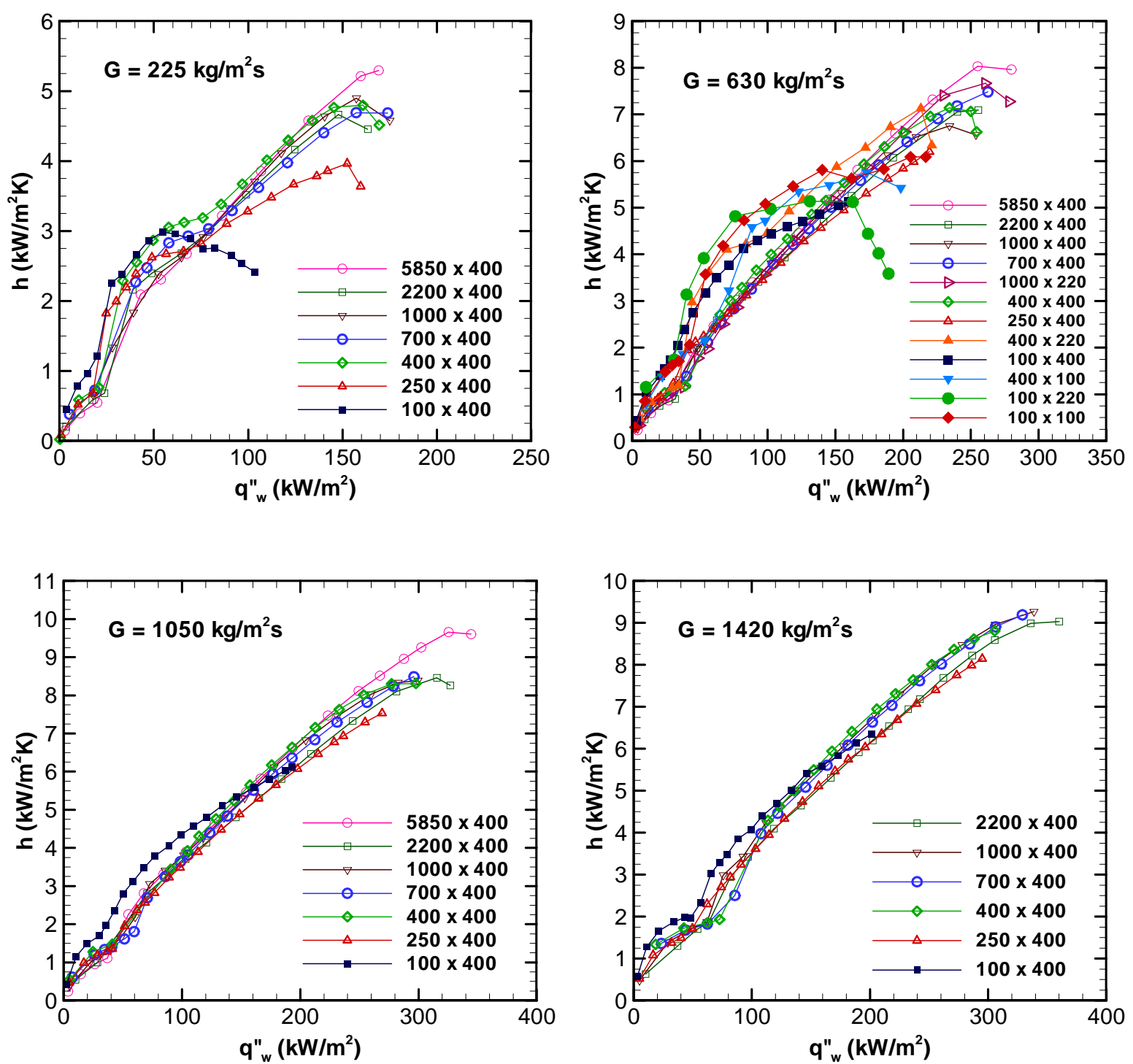

Figure 6. Effects of physical confinement on heat transfer coefficients for four mass fluxes; the microchannel dimensions are presented as width $(\mu \mathrm{m}) \times$ depth $(\mu \mathrm{m})$. 


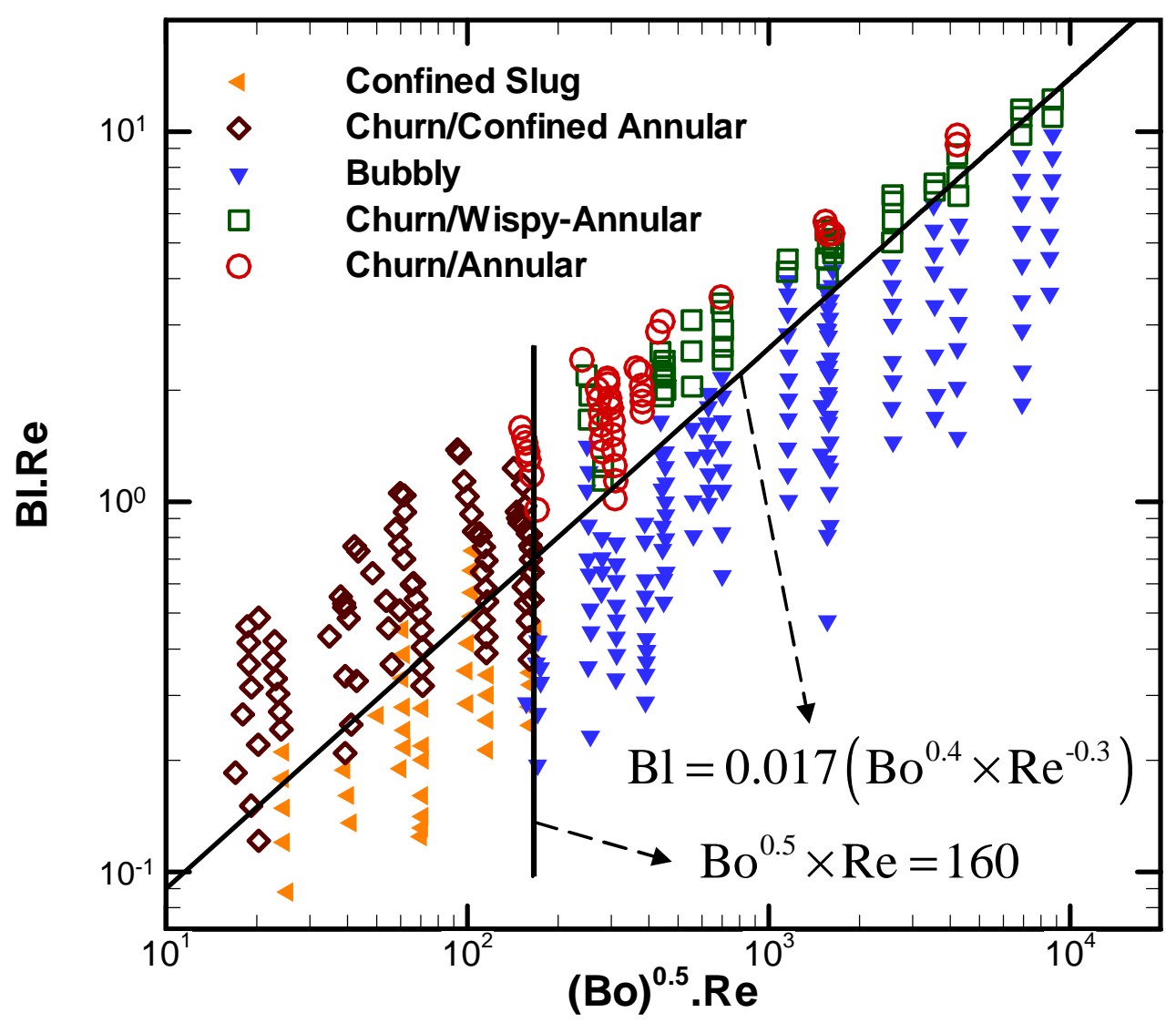

Figure 7. Comprehensive flow regime map for FC-77. 


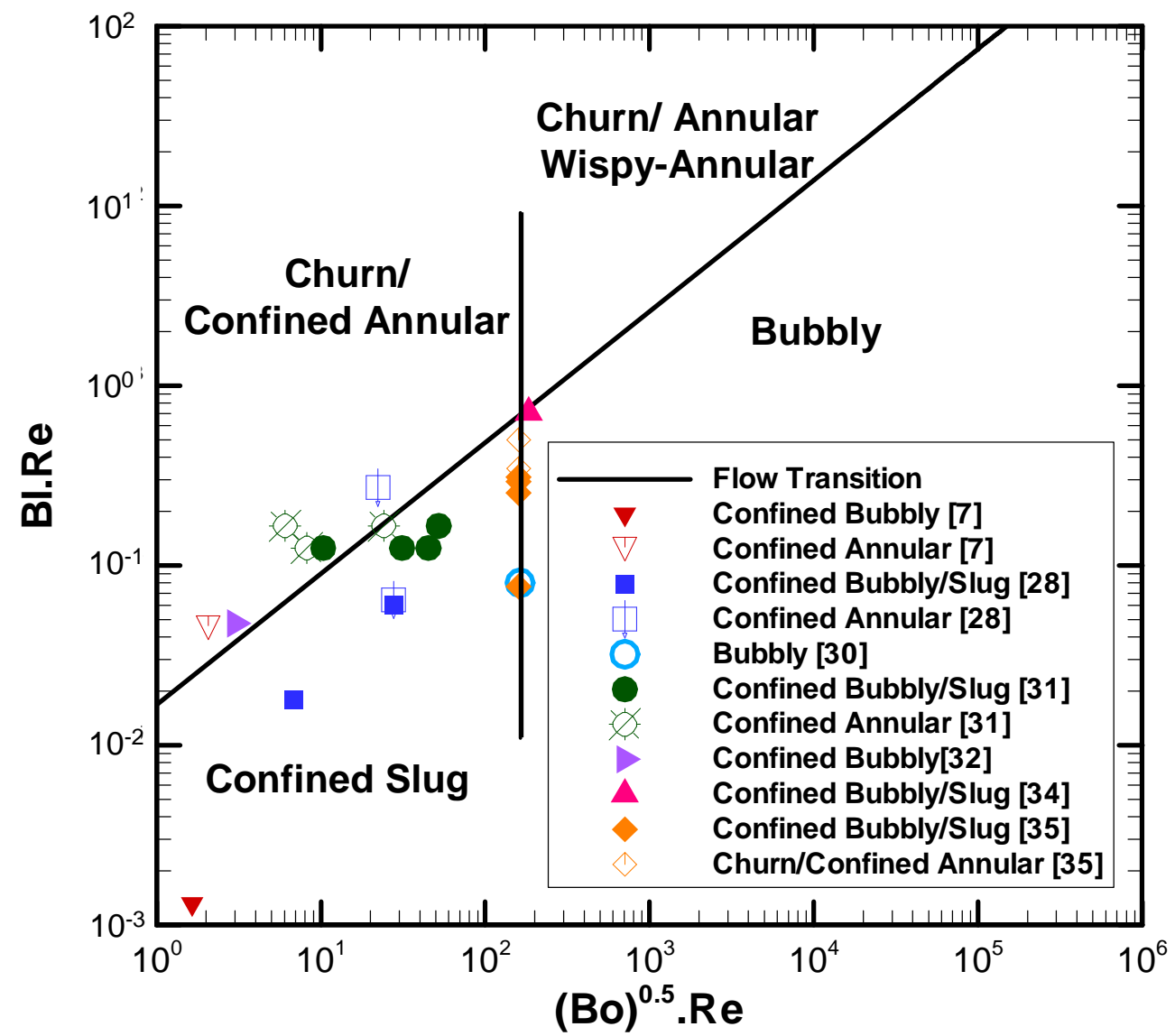

Figure 8. Comparison of the comprehensive flow regime map with the experimental data from the literature. 